\title{
MICROSTRUCTURAL INSIGHTS INTO THE PETROPHYSICAL CHARACTERISTICS OF INDURATED CLAYS
}

\author{
P. Marschall ${ }^{1, *}$, L. Keller ${ }^{2}$, S.B. Giger ${ }^{1}$, and J. Becker ${ }^{1}$ \\ ${ }^{1}$ National Cooperative for the Disposal of Radioactive Waste, \\ 5430 Wettingen, Switzerland \\ ${ }^{2}$ ZHAW/ICP, Wildbachstrasse 21, 8401 Winterthur, Switzerland \\ *e-mail: paul.marschall@nagra.ch
}

\begin{abstract}
Core samples from the Opalinus Clay, an indurated clay formation of Jurassic age, were subjected to comprehensive microstructural investigations: transmission electron microscopy, focused ion beam nanotomography, and X-ray computed tomography. Digital representations of the microstructure were derived from the tomographic images by segmentation and 3D reconstruction of the geomaterial on a grid of regular voxel elements with a typical edge length of as little as $10 \mathrm{~nm}$ and a maximum size on the order of $1000^{3}$ voxels. Pertinent geotechnical properties were derived on the microscopic scale using state-of-the-art image-processing procedures. The results were compared with results from geotechnical laboratory characterization methods such as mercury intrusion porosimetry, nitrogen adsorption/desorption measurements, grain-size analysis, X-ray diffraction, and triaxial testing. Good agreement was achieved between microscopic and macroscopic characterization methods. The macroscopic (poro-elastic) deformation behavior of the Opalinus Clay was also reproduced reasonably well by geomechanical modeling on the microscopic scale. The cross-anisotropic stiffness of the rock mass is thus caused partly by preferred orientation of pore structures along bedding. In addition, new insight was gained with regard to the role of small mesopores $(2-10 \mathrm{~nm})$, essentially controlling the macroscopic deformation behavior of indurated clays.
\end{abstract}

\section{Introduction}

Indurated clays, such as claystones and shales, are considered to be potential host-rock formations for the disposal of radioactive waste. Favorable features are their excellent hydraulic barrier function and their retention capacity for dissolved radionuclides, together with a significant self-sealing capacity. The peculiar petrophysical characteristics of this class of fine-grained argillaceous sediments on the macroscopic scale originate essentially from their microscopic structure, which was formed by diagenetic processes under the impact of the depositional environment, the stress experienced, and the temperature history. The mineralogical composition and bonding of the grains, as well as the geometry and connectedness of the intergranular pore space around the solid skeleton, are of utmost importance for the hydro-mechanical behavior of indurated clays at the macroscopic scale, expressed essentially in terms of porosity, hydraulic conductivity, poro-elastic rock properties (e.g. drained and undrained elastic 
moduli, Biot- and Skempton-coefficient), and rock strength (drained and undrained strength parameters). The present study is dedicated to the derivation of scaling procedures, allowing for the inference of macroscopic poro-mechanical properties from a detailed knowledge of microstructural characteristics of clay-rich geomaterials.

\section{Geotechnical characteristics of the Opalinus Clay}

Opalinus Clay in the Molasse Basin and in the Jura Fold and Thrust Belt of northern Switzerland has been proposed as a candidate host rock for a radioactive waste repository in Switzerland. It is a moderately to heavily over-consolidated claystone $(1.5 \leq$ OCR $\leq 5)$ (OCR - overconsolidation ratio, i.e. maximum burial depth/recent burial depth) with a clay-mineral content of between 40 and $75 \%$, a quartz content of between 10 and $30 \%$, and a carbonate content of between 5 and $35 \%$ (Figure 1a). The porosity displays moderate depth dependence with typical values of $8-16 \%$ (corresponding to an overburden of several hundred meters). Hydraulic conductivity derived from laboratory and in situ testing exhibits typical values of between $10^{-12}$ and $10^{-14} \mathrm{~m} / \mathrm{s}$ and conforms well to empirical permeability correlations, drawing on measurements of porosity and claymineral content (Yang and Aplin, 2010). Based on grain-size distribution, the Opalinus Clay is classified as a clayey (and sandy) siltstone (Figure 1b). The consistency behavior (Atterberg limits) provides additional insight into the intrinsic geomechanical properties of the (destructured) geomaterial, representing a qualitative indicator for the friction angle. As shown in Figure 1c, the plasticity index plots broadly along the A-line of the plasticity chart, which separates clayey from silty soils. The values reported for liquid limit, $w_{\mathrm{L}}$, and plasticity index, PI, range from $\sim 30$ to $50 \%$ and $\sim 10$ to $25 \%$, respectively. Drawing on empirical correlations by Terzaghi et al. (1996) and Stark and Eid (1994), the friction angle of the Opalinus Clay can be bracketed in the range between 20 and $35^{\circ}$, which is in good agreement with findings from geomechanical testing.

In terms of mechanical behavior, the Opalinus Clay displays features characteristic of both a (stiff) soil and a (weak) rock. One-dimensional (oedometric) consolidation testing shows a significant volume reduction in the stress range above the preconsolidation stress (20-25 MPa for core samples in northern Switzerland). Results of 'Unconfined Compressive Strength' tests suggest a weak to medium-strong rock with distinct anisotropy (loading parallel and normal to bedding: $\mathrm{UCS}_{\mathrm{p}, \mathrm{n}}=12-40 \mathrm{MPa}$; loading oblique to bedding: $\mathrm{UCS}_{\mathrm{z}}=5-20 \mathrm{MPa}$, Figure 1d). Strain softening and development of discrete shear surfaces are typically observed in undrained triaxial testing. The (undrained) Young's moduli were found to be stress dependent and anisotropic for values measured parallel to and normal to bedding $\left(E_{\mathrm{p}}=5-20 \mathrm{GPa}, E_{\mathrm{n}}=2-10 \mathrm{GPa}\right)$.

\section{Results and discussion}

Microstructural investigations of Opalinus Clay samples from a deep geothermal well in northeastern Switzerland (located near the village of Schlattingen) and from the Mont 
a

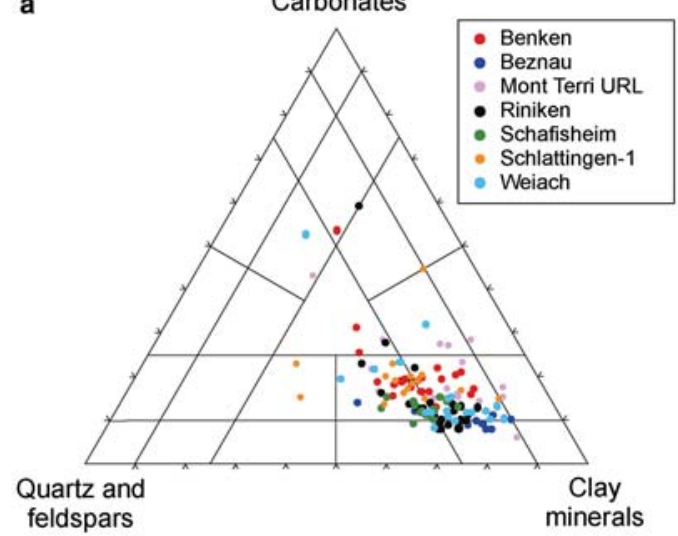

c

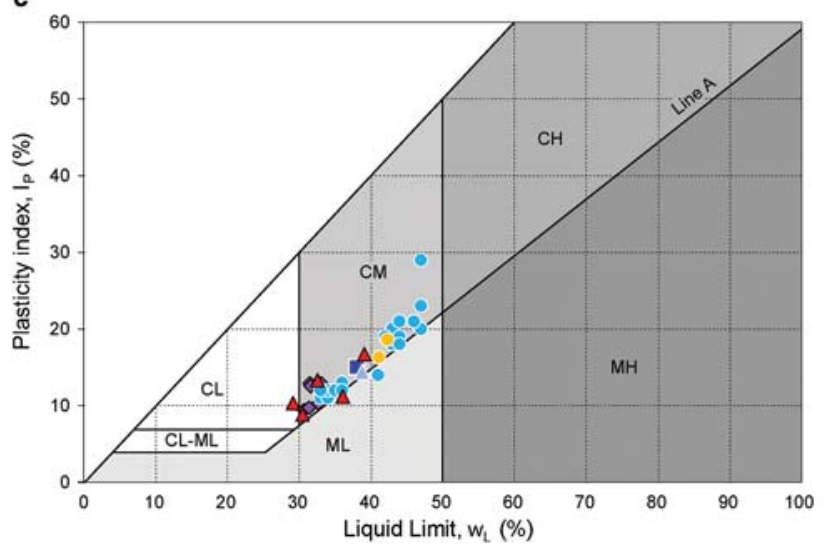

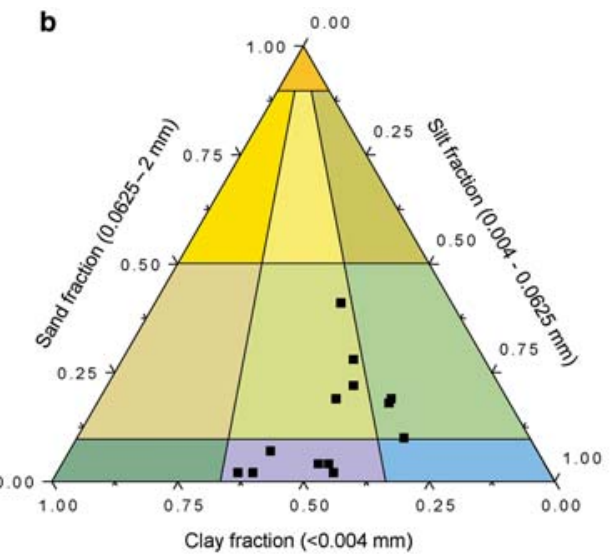

$\square$ Orthosandstone

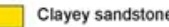

Clayey silty sandstone

Silty sandstone

Sandy claystone

Clayey sandy siltstone

Sandy siltstone

Claystone

Clayey siltstone

Siltstone

d

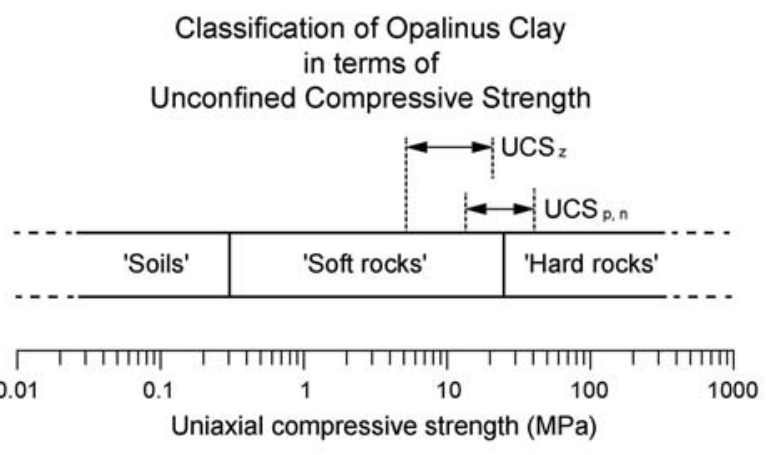

Figure 1. Classification of the Opalinus Clay in terms of mineralogy, grain size, and consistency: (a) ternary diagram of principal mineralogical components; (b) USCS classification of fine-grained sedimentary rocks; (c) plasticity chart (SN 670 004-2a); and (d) Unconfined Compressive Strength after Gens (2013). 
Terri underground laboratory (located in the Jura Fold and Thrust Belt) were conducted by Keller et al. (2013a, 2013b). The investigations consisted of multi-scale characterization of the samples by X-ray computed tomography (XCT), focused ion beam nanotomography (FIB-nt), and scanning transmission electron microscopy (TEM), followed by segmentation and reconstruction of the rock fabric (Figure 2). The reconstructed digital representation of the microstructure with a maximum size on the order of $1000^{3}$ voxels was then subjected to quantitative data analyses and model simulations. The analyses included: estimations of the pore-size distribution, water-retention behavior, and grain-size distribution; the derivation of representative elementary volumes (REV) of porosity (Keller et al., 2013a), clay content (Keller, 2015), pore connectivity, capillary properties, permeability on the basis of numerical channel network simulations (Keller et al., 2013a), and impact of sand fraction on solute diffusion (Keller et al., 2015); and, finally, simulations of the undrained and drained poro-elastic properties.

a

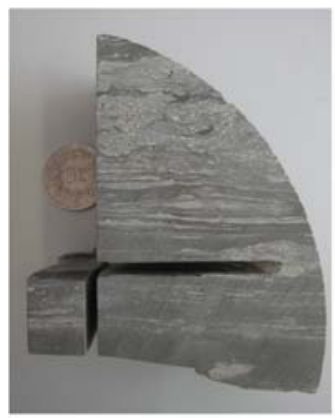

C

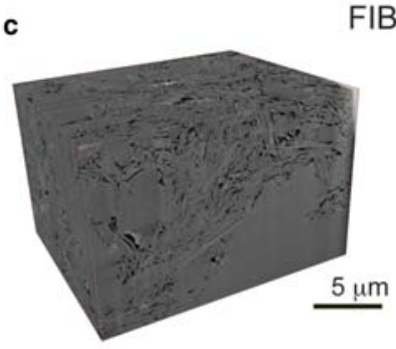

b

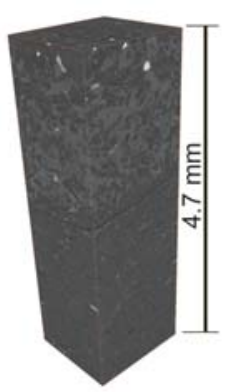

FIB-nt

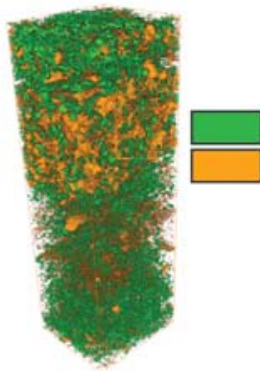

Quartz (14 vol. \%)

Carbonates (12 vol. \%)

\section{d STEM}

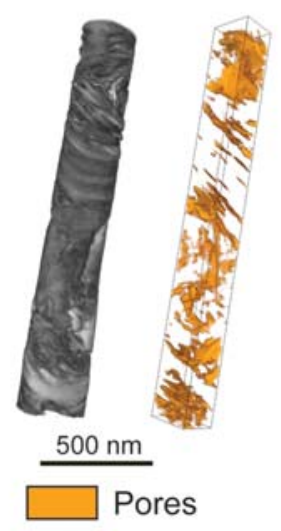

Figure 2. Microstructural characterization of Opalinus Clay: (a) image of a core sample which contains carbonate/quartz-rich and clay-rich layers at various scales; (b) X-ray tomography data of a thin slab from the sample and 3D reconstruction of the mineral components (green - quartz; orange - carbonates); (c) FIB-nanotomography and visualization of connected/unconnected pore space (green - connected pore space; orange - unconnected pores); and (d) scanning transmission electron microscopy (TEM) and visualization of pore space. 


\subsection{Porosity and pore-size distribution}

Samples from different lithofacies of the Opalinus Clay formation (sandy, shaley, and carbonate-rich facies) were analyzed by FIB-nt and TEM. Statistical analyses of the segmented 3D reconstructions by simple box-counting approaches allowed for the derivation of equivalent pore-size distributions (Figure 3a). Thus, REV values of porosity and pore connectivity (representing an indicator of permeability) were derived, using the conceptual framework of the local porosity theory (Kanit et al., 2003; see also Keller et al., 2013a). The results of this geometric analysis (drawing on image-processing procedures) were compared with classical geotechnical methods, such as mercury intrusion porosimetry, water-retention measurements, and nitrogen adsorption/ desorption measurements (BET - Brunauer et al., 1938). The different methods reveal, in a consistent manner, the distinct differences in the pore-size distribution of the three
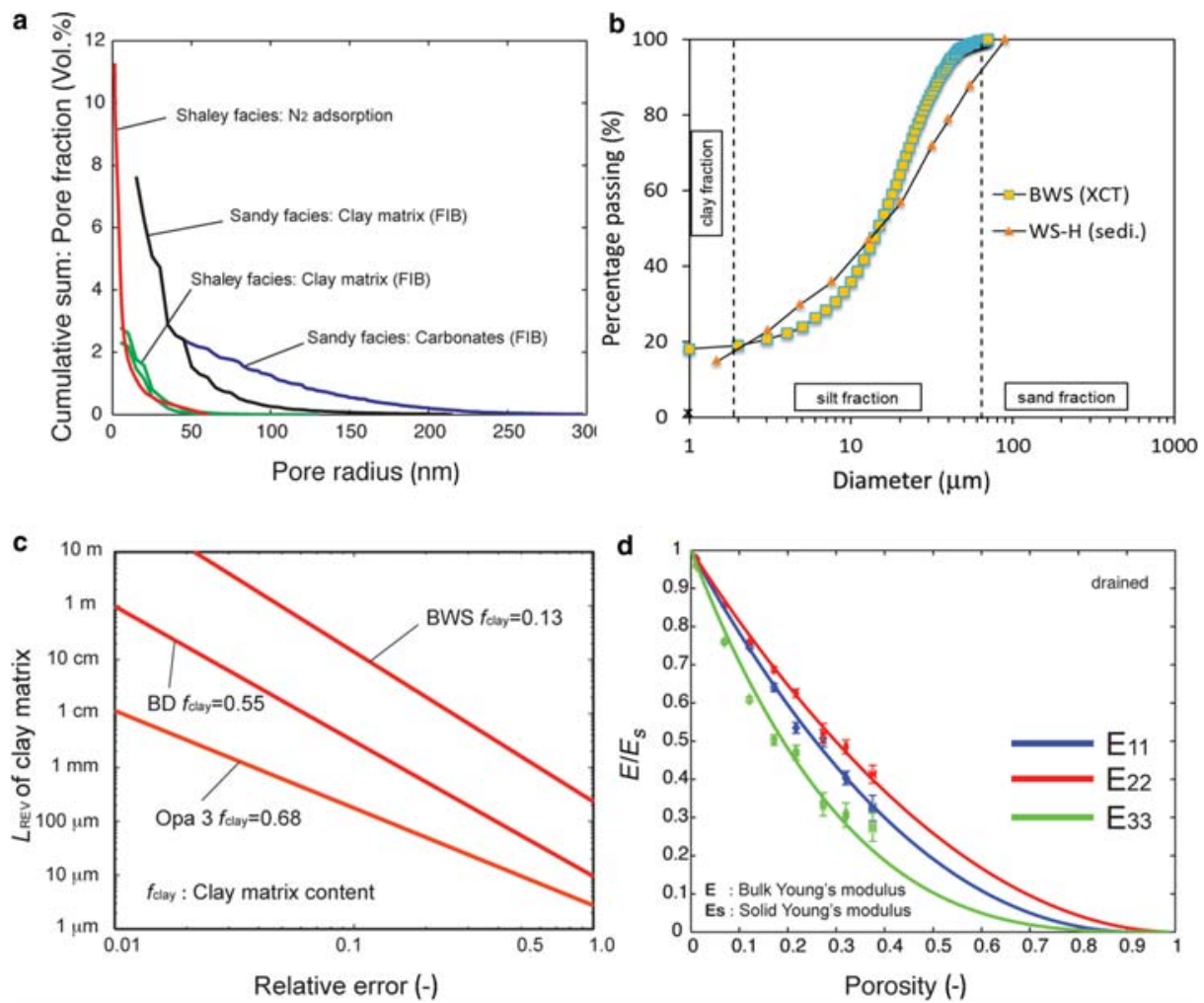

Figure 3. Properties extracted from FIB-nt and XCT data: (a) calculated pore-size distributions (shaley, sandy, and carbonate-rich facies) and comparison with $\mathrm{N}_{2}$ adsorption data; (b) grain-size distributions of Opalinus Clay samples from Mont Terri (WS-H borehole), derived from XCT image analysis and grainsize analysis, respectively; (c) estimated REV for clay mineral content; and (d) ratio between bulk and solid Young's moduli parallel $\left(E_{11}\right.$ and $\left.E_{22}\right)$ and normal $\left(E_{33}\right)$ to bedding derived using numerical simulations. 
facies. The shaley facies contains mainly micro- and small meso-pores $(<10 \mathrm{~nm}$; definitions according to IUPAC, 1997). The resolved porosity in the clay matrix of the sandy facies is greater and the pores are larger when compared to the shaley facies. Larger intergranular pores can often be observed around the quartz and carbonate grains (note that the spatial resolution of FIB-nt is on the order of $10 \mathrm{~nm}$ and $\sim 5 \mathrm{~nm}$ for TEM).

\subsection{Grain-size distribution and mineralogical composition}

The methods of sieving and sedimentation (clay, silt, and sand fractions in wt.\%) are standard geotechnical procedures for measuring the grain-size distribution of fine soils. The mineralogical composition of the geomaterial in terms of principal mineralogical components (clay, quartz, carbonates in wt.\%) is typically determined by X-ray diffraction (XRD). Quantitative analyses of microstructural investigations with XCT and FIB-nt have been used as complementary approaches for the classification (see Figure 1) and characterization of the Opalinus Clay with respect to mineralogy and granulometry. Segmented 3D reconstructions of the samples investigated were analyzed using the aforementioned image-processing procedures, aimed at deriving grain-size distributions and clay-mineral content with an independent measuring approach. The results of the geometric analyses were compared with classical geotechnical methods. The grain-size distribution of the core sample WS-H from Mont Terri derived by grain-size analysis (Minon et al., 2010) was compared with the results of sample BWS from the same borehole, deduced from statistical analysis of XCT-based sample reconstruction, in Figure $3 \mathrm{~b}$. The different characterization techniques provided comparable results, classifying the samples as (sandy) siltstone according to the scheme in Figure 1a. On the basis of synchrotron XCT, the analysis of the REV of clay-matrix content of the three core samples OPA3, BD, and BWS is shown in Figure 3 (note, the REV is defined according to Kanit et al. (2003) as the minimum volume for which the variance of the clay-matrix content determined for one realization is sufficiently small). The REV of the clay-matrix content depends heavily on the volume fraction. For a claymatrix content of $68 \mathrm{vol} . \%$ and by accepting a relative error of $10 \%$ on the reference bulk clay matrix content, the size of the REV of sample OPA3 is $\sim 100 \mu \mathrm{m}$ (Keller et al., 2015). The mean clay content derived on the basis of XCT images conforms very well with the results of mineralogical analyses of the same sample carried out using classical XRD methods ( $c_{\text {clay,XRD }}=62 \%$; see also Keller et al., 2015).

\subsection{Deformation behavior}

Sub-volume samples of the reconstructed FIB-nt data sets were used in a geomechanical FE-model to reproduce the macroscopic (poro-elastic) deformation behavior of the Opalinus Clay. For a typical sample from the shaley facies, the relationship between porosity and Young's/shear moduli appears to be a well known power-law relationship (Figure 3d). In addition, a polar anisotropy in elastic properties was revealed which is related to a preferred orientation of pore structures parallel to bedding. Elastic properties are nearly isotropic within planes parallel to bedding but are substantially different 
perpendicular to bedding. In particular, with increasing porosity, the Young's modulus that accounts for stiffness perpendicular to bedding decreases much more when compared to those that account for stiffness within the bedding plane. Drainage of water from the pores enhances this effect as it reduces substantially the stiffness perpendicular to bedding.

With regarding to the application of a shear strain, the material also exhibits a different response when shear stress is applied in different directions. The shear modulus is greater when shear strain occurs due to forces acting on a plane perpendicular to bedding but is less when the shear plane is parallel to bedding. The effect of drainage on shear moduli is minor and does not increase by much the anisotropic response to shear strain. Drainage of water reduces substantially the two Poisson's ratios which measure the ratio between strain parallel and perpendicular to bedding.

The effects of pores on elastic properties were determined on the basis of small sample volumes; as a result, the question is raised regarding the finite size error related to the elastic constants determined. In other words, the question was tackled regarding the size of the REV of the elastic constants related to the clay matrix. Again, this question was answered using the statistical approach of Kanit et al. (2003). In the case of a cubic FIB-nt sample with an edge length of $2.8 \mu \mathrm{m}$, an error of $\sim 6 \%$ was expected for a single realization. Note that in the case of several realizations, the error decreased substantially. When elastic properties are considered, the sample size related to FIB-nt is, therefore, apparently sufficient to provide relevant information.

\section{Summary and conclusions}

Statistical analyses of 3D digital reconstructions of FIB-nt and XCT data were conducted to estimate pore-size distribution, porosity, pore connectivity, and mineral content (clay fraction, quartz, carbonates) and the associated REVs of Opalinus Clay samples from different lithofacies. The results of this geometric analysis (drawing on image-processing procedures) compare well with classical geotechnical methods, based on mercury intrusion porosimetry, BET, and XRD. Modeling of effective elastic properties on the microscale using a finite element code provided insights into the effects of pore morphology and drainage on elastic properties. The model results revealed cross-anisotropic stiffness, which is related to preferred orientation of pore structures. This anisotropy of the pore space will probably contribute to the overall macroscopic cross-anisotropic stiffness. New insight regarding the drained/undrained poro-elastic behavior was gained, indicating that the spatial distribution and connectivity of the small mesopores $(2-10 \mathrm{~nm}$; IUPAC, 1997) are essentially controlling the macroscopic deformation behavior of indurated clays. This appears to be in line with Terzaghi's theory of adsorbed water films, postulating that the pore water in the small mesopores is not free but is weakly bound to the surfaces of the mineral aggregates (diffuse double layer). The water viscosity and effective water compressibility, therefore, start to deviate from the reference values of free water with significant impact on the drained deformation behavior of the material. 


\section{Acknowledgments}

The authors thank Prof. L. Laloui, Dr A. Ferrari, and V. Favero (all LMS/EPFL Lausanne, Switzerland) for comprehensive geotechnical characterization of the core specimen. This work was funded partly by the SHARC consortium, a research collaboration between the Commonwealth Scientific and Industrial Research Organization (CSIRO), Curtin University of Technology (Australia), and NAGRA (Switzerland).

Guest editor: Reiner Dohrmann

The authors and editors are grateful to anonymous reviewers who offered very helpful input and suggestions. A list of all reviewers is given at the end of the Preface for this volume.

\section{References}

Brunauer, S.E., Emmett, P.H., and Teller, E. (1938) Adsorption of gases in multimolecular layers. Journal of the American Chemical Society, 60, 309-319.

Gens, A. (2013) On the hydromechanical behaviour of argillaceous hard soils-weak rocks. Proceedings of the $15^{\text {th }}$ European Conference on Soil Mechanics and Geotechnical Engineering. Geotechnics of Hard Soils - Weak Rocks (Part 4).

IUPAC (1997) Compendium of Chemical Terminology, The Gold Book, second edition. (A.D. McNaught and A. Wilkinson, editors). Blackwell Science, London.

Kanit, T., Forest, S., Gailliet, I., Mounoury, V., and Jeulin, D. (2003) Determination of the representative volume for random composites: statistical and numerical approach. International Journal of Solids and Structures, 40, 3647-3679.

Keller, L.M., Schuetz, P., Gasser, P., and Holzer, L. (2013a) Pore-space relevant for gas permeability in Opalinus Clay: statistical analysis of homogeneity, percolation and representative volume element (RVE). Journal of Geophysical Research, 118, 1-14.

Keller, L.M., Schuetz, P., Erni, R., Rossell, M.D., Lucas, F., Gasser, P., and Holzer, L. (2013b) Characterization of multi-scale microstructural features in Opalinus Clay. Microporous and Mesoporous Materials, 179, 83-94.

Keller, L.M., Hilger, A., and Manke, I. (2015) Impact of sand content on solute diffusion in Opalinus Clay. Applied Clay Science, 112-113, 134-142.

Keller, L.M. (2015) On the representative elementary volume of clay rocks at the mesoscale. Journal of Geology and Mining Research, 7, 58-64.

Minon, S., Salager, S., and Laloui, L. (2010) WS-H Experiment: Identification tests and rheological analysis of Opalinus Clay: Shaley facies, Sandy facies and Wet Spot material. Mont Terri Technical Note TN 2010-61.

Stark, T.D. and Eid, H.T. (1994) Drained residual strength of cohesive soils. Journal of Geotechnical Engineering, 120/5, 856-871.

Terzaghi, K., Peck, R.B., and Mesri, G. (1996) Soil Mechanics in Engineering Practice, third edition. John Wiley \& Sons, New York.

Yang, Y.L. and Aplin, A.C. (2010) A permeability-porosity relationship for mudstones. Marine and Petroleum Geology, 27, 1692-1697. 